\title{
Practices in the healthcare of children and adolescents with leprosy: the discourse of professionals
}

\author{
Práticas de atenção à saúde de crianças e adolescentes \\ com hanseníase: discursos de profissionais \\ Prácticas de atención médica para niños y adolescentes: \\ discursos profesionales
}

\author{
Joana D'Arc Conceição Pinheiro de Oliveira ${ }^{a}$ \\ Maria Wanderleya de Lavor Coriolano Marinus ${ }^{b}$ \\ Estela Maria Leite Meirelles Monteiro ${ }^{b}$
}

\section{How to cite this article:} Oliveira JDCP, Marinus MWLC, Monteiro EMLM. Practices in the healthcare of children and adolescents with leprosy: the discourse of professionals. Rev Gaúcha Enferm. 2020;41:e20190412 doi: https://doi.org/10.1590/19831447.2020.20190412
Universidade Federal de Pernambuco (UFPE), Programa de Pós-graduação em Saúde da Criança e do Adolescente. Recife, Pernambuco, Brasil.

${ }^{\circ}$ Universidade Federal de Pernambuco (UFPE), Departamento de Enfermagem. Recife, Pernambuco, Brasil.

\section{ABSTRACT}

Objective: To analyze the health care practices of children and adolescents with leprosy from the speeches of health professionals. Method: Qualitative research conducted with 23 health professionals who attended children and adolescents with leprosy in primary and secondary care in a municipality in the state of Pernambuco, from April to July 2018, through semi-structured interviews. Data were subjected to content analysis.

Results: The practice of health care was apprehended from the following categories of analysis: "Embracement in leprosy", "Clinical practice" and "Education in Health", with limitations in meeting the particularities of the studied population.

Conclusions: Limiting aspects in health care practice contribute to the difficulties in controlling the disease, requiring the development of best practice recommendations that address the needs of children and adolescents.

Keywords: Leprosy. Child. Adolescent. Public health practice. Health education.

\section{RESUMO}

Objetivo: Analisar as práticas de atenção à saúde de crianças e adolescentes com hanseníase, a partir dos discursos de profissionais de saúde.

Método: Pesquisa qualitativa, realizada com 23 profissionais de saúde que atendiam crianças e adolescentes com hanseníase na atenção básica e secundária de um município do Estado de Pernambuco, de abril a julho de 2018, mediante entrevistas semiestruturadas. Os dados foram submetidos a análise de conteúdo.

Resultados: A prática de atenção à saúde foi apreendida a partir das seguintes categorias de análise: "Acolhimento em hanseníase", "A prática clínica" e"Educação em saúde", com limitações no atendimento às especificidades do público estudado.

Conclusões: 0 s aspectos limitantes na prática de atenção à saúde contribuem para as dificuldades no controle da doença, requerendo 0 desenvolvimento de recomendações de boas práticas que contemplem as necessidades de crianças e adolescentes.

Palavras-chave: Hanseníase. Criança. Adolescente. Prática de saúde pública. Educação em saúde.

\section{RESUMEN}

Objetivo: Analizar las prácticas de atención de la salud de niños y adolescentes con lepra, a partir de los discursos de los profesionales de la salud.

Método: Investigación cualitativa realizada con 23 profesionales de la salud que atendieron niños y adolescentes con lepra en atención primaria y secundaria en un municipio del estado de Pernambuco, de abril a julio de 2018, a través de entrevistas semiestructuradas. Los datos fueron sometidos a análisis de contenido.

Resultados: La práctica de la atención de la salud fue aprehendida de las siguientes categorías de análisis: "Recepción en la lepra", "Práctica clínica"y"Educación en salud", con limitaciones para satisfacer las especificidades de la población estudiada.

Conclusiones: Los aspectos limitantes en la práctica del cuidado de la salud contribuyen a las dificultades para controlar la enfermedad, lo que requiere el desarrollo de recomendaciones de mejores prácticas que aborden las necesidades de los niños y adolescentes.

Palabras clave: Lepra. Niño. Adolescente. Práctica de salud pública. Educación en salud 


\section{口INTRODUCTION}

Leprosy, despite being a thousand-year-old disease, is still endemic in developing countries. It can affect everyone, from children to elders. It presents a high potential of generating disability, especially when it affects infants or adolescents, since these are the stages of human growth and development ${ }^{(1)}$.

Globally, in 2018,208,613 new cases have been registered. In Brazil, there were 28,660 cases, a general detection rate of 13.70/100,000 people.1,705 were new cases, registered in people younger than 15 years old ${ }^{(2)}$. In the same year, the Northeast was found to be the Brazilian region with the highest number of notifications in children 15 years old or younger, with 802 new cases. Pernambuco was the second state with the highest number ${ }^{(3)}$.

When it affects children and adolescents, leprosy is more prevalent in the age group from 5 to 14 years of age, and in up to $6 \%$ of cases, it affects those younger than 5 years old. A study carried out with this population shows that the fact it more frequently affects older children can be explained due to the long period of incubation of the disease (3-7 years), and to the difficulties of the professionals in evaluating the loss of sensitivity in children, which can delay a diagnosti ${ }^{(4)}$.

The inadequate management of the disease or the delay in the diagnostic can compromise the health of this population, causing permanent deformities and disabilities, leading to changes in life. These changes affect daily life activities and leisure, be it because of the collateral effects of medications, or because of social discrimination. As a result, public policies are needed that take into account the health demands of this public ${ }^{(5)}$. To this end, a Brazilian study ${ }^{(3)}$ points out the importance of improving actions for the healthcare of children and adolescents with leprosy, to break the chain of transmission and the high endemicity of the disease in the country.

Therefore, recognizing the particularities of the children and adolescent population in the improvement of actions to surveil and control leprosy, the multidisciplinary health team is an essential instrument to revisit these healthcare practices, with emphasis in the managerial role of the nurse in the development of integral care ${ }^{(5-6)}$. Healthcare is a complex type of work, built within a historical and social context. Its main result is immaterial and produced through relations established between the professional and the user. The analysis of power relations is one of the pillars of the work of Michel Foucault; in this universe, they are described as relations present everywhere, in all types of interactions between people, including in health.

The power can, also, assume many different representations and meanings. In this context, analogous to Foucauldian thought, the health system can be translated as a legal-discursive representation of power. Legal because it is modeled by laws, norms, protocols. Discursive because its norms are linked to what can be said and done. Therefore, it is connected to both language and actions $s^{(7)}$.

The discourse is a representation culturally built by reality as opposed to a perfect copy, since it is regulated by the production of categories of knowledge and groups of texts. It determines what can be spoken and what cannot, in accordance to the rules established. As such, it (re)produces power and knowledge simultaneously ${ }^{(8)}$. The discourse, the exchange of knowledge, and communication are shown as positive figures, that act as to translate the meanings and subjectivities that manifest or hide in the relations between individuals $^{(9)}$.

Healthcare practices are based on priority actions carried out in the daily attention to the community. These practices, when developed targeting children and adolescents with leprosy, represent a set of devices that, according to the Foucauldian concept, include dynamic and articulated elements that group the instances of power in which discourses, institutions, laws, administrative measures, and moral propositions are included. Consequently, the devices move according to the networks of power, and can express the subjectivities of the subjects involved in said network ${ }^{(7-9)}$.

The concern that led to the development of this investigation stemmed from the perception that this disease is still, from both a national and an international perspective, a public health problem, with an increase in the number of cases in the population studied. There are also limitations related to previous researches that revisit the context of the professional practice in the healthcare to children and adolescents being treated for leprosy.

With the interest of acquiring significant knowledge regarding the practices in the healthcare of children and adolescents with leprosy, the following question emerged: what are the practices in the healthcare to children and adolescents with leprosy, according to the discourse of health professionals?

Considering this, this study aims to analyze the healthcare practices of children and adolescents with leprosy, considering the discourse of health professionals. 


\section{METHOD}

This is a descriptive, qualitative study, carried out in Family Health Units (USF) and Specialized Services in treatment of leprosy in a city in the state of Pernambuco, and originates from a dissertation. The qualitative approach was chosen due to its capacity for incorporating the meaning and the intentions of relations and social structures. It makes possible to capture the deeper levels of the investigation, which cannot be translated into statistical data ${ }^{(10)}$.

The study was carried out in areas that are highly endemic for the disease in 15 year-olds, according to epidemiological criteria found through the Information System for the Notification of Health Problems (Sinan), which generates a priority mapping of the sanitary districts (SD) II and IV. Three USF and two Specialized Services from these districts were included in the study, since they presented a higher number of new cases of leprosy in children and adolescents from 2012 to 2017. The USFs, as well as the Specialized Services and the Enhanced Centers of Family Health and Primary Care (NASF$A B)$ were included in the investigation, based on decree No. 149 from 2016, which regulates the Attention Networks for people affected by leprosy. The decree considers that actions for endemic control should be carried out through the entire primary healthcare network of the Single Health System (SUS).

The participants were health professionals from the multidisciplinary team that helped children and adolescents with leprosy through consultations or home visits. The selection of the health professionals attended the following inclusion criteria: 1) having worked for at least 6 (six) months in the Family Health Units or in the Specialized Services; 2 ) helping children and adolescents with leprosy through consultations. The study excluded the professionals who were absent from the service during data collection due to vacations, sick leaves, or any other reason. The sample was intentional, and the criteria of theoretical saturation was used to define sample size. Data collection took place from April to July 2018.

The semistructured interview was used in this research as a data collection technique, and was guided by a script with the following guiding questions: On average, how long are the consultations of children/adolescents with leprosy? What procedures regarding clinical practice are carried out in the consultation? How is the patient welcomed in their first consultation in the unit? How is the relationship/bond between professional and patient established? Is there any difficulty/limiting factor in the attention to children/adolescents with leprosy? If so, what is it? Is there any factor that makes your practice of assistance easier? If so, what is it? How is health education in leprosy offered to the children adolescents being cared for?

The interviews were carried out in the work environment of the professionals, in a private room. They were carried out by one of the authors of the study. Interviews were recorded using two audio recorder devices, a digital recorder (Sony Digital Voice Recorder) and a portable recorder (Smart Voice Recorder) and transcribed entirely to subsidize the stage of data presentation and analysis.

Data were analyzed using Bardin ${ }^{(11)}$ structured content analysis, which is a set of techniques for the analysis of communication based in systematic and objective procedures for the description of the contents of the messages. This systematization, as well as the organization of the analysis, took place in three moments, starting with a pre-analysis, followed by material exploration, and finally, the treatment and interpretation of the results obtained. The second stage, which corresponds to the exploration of the material, counted on the aid of the software Atlas.ti for Windows (Version 8.0), which aids the researcher in the coding and organizing of the data analysis.

The coding, from the statements of the participants, subsidized the analytical grouping in three distinct thematic categories: "Embracement in leprosy"; "Clinical practice"; and "Education in health". The corpus acquired from the discourse of the professionals subsidized the elaboration of these categories, which were elaborated from the contents of the discourses of the participants, considering structuring elements of philosophical Foucaultian underpinnings, such as power, care, and discourse $\mathrm{e}^{(7-9,12-13)}$.

The research was approved by the Ethics Committee for Researches with Human Beings (CEP) from the Center of Health Sciences (CCS) of the Universidade Federal de Pernambuco (UFPE), under certificate No. 81181417.2.0000.5208 and protocol No. 2.532.172, following the prescriptions of Resolution 466/12 and its complements. A formal agreement to participate was asked from the participants in the form of the Free and Informed Consent Form (FICF).

To maintain the anonymity of the participants, their names were replaced by codes formed by a sequence of letters and numbers. The letters correspond to the professional category of each participant. The letters are followed by numbers identifying the order in which the participant was interviewed in the research. To continue with the coding sequence, a second set of letters was used, which were " $F$ " for female and " $M$ " for male, followed, finally, by the age of the interviewee. 


\section{RESULTS AND DISCUSSION}

The discourse of 23 graduated health professionals was recorded. They were from the USF, from Specialized Services, and from the NASF-AB. Among them, there were eight (08) nurses, ten (10) physicians, two (2) physical therapists, one (01) occupational therapist, and two (02) psychologists. The participants, with regards to their professional formation, had finished specialization post-graduation courses, health residencies, and master's degrees in the fields of dermatology, hansenology, public health, family health, children and/or adolescent health, as well as some further training courses on leprosy offered by the municipal administration.

\section{Embracement in leprosy}

Embracement within the SUS can be characterized as an ethical posture, assumed by health workers, which is involved with all moments of user care and leads to qualified listening, considering individual complains and needs ${ }^{(14)}$. For users to be embraced by multidisciplinary health professionals, demands regarding the work environment must be considered, such as: the time available for each consultation with regards to the demands; the communication with the child/adolescent and the family; how accessible the service is; and the adherence to the treatment with the multidisciplinary attention.

The participants in the study, in their statements, linked the time used in consultation to their routine daily activities of attention for leprosy, considering that it is mandatory to notify cases of leprosy.

(P5 - F30) [...] it's always a longer consultation, because in addition to examine, to see the problems of the patient, we need to know what got in touch with them, to try and understand how this patient got contaminated, and we need to do all the paperwork for the notification, for the prescriptions, sometimes refer to the dermatologist.

The workers talked about the communication they establish with the child and/or adolescent and the family or caretaker, stating that the discourse of the users presents itself as a guiding element of the healthcare practices in leprosy. They also highlighted how important it is for the professional to use a playful language, to understand the universe of both the children and the adolescents.

(OT1 - F48) [...] their discourses are guides. They are related to our practice, the patient making their demands, they know what they want. The discourse is determinant, since the father/mother/guardian brought the them because someone said something or, if they did not, we are supposed to observe and try to listen that child or adolescent.

(PSY1 - F51) With children there is a way, with adolescents there is another [...] / like using a game sometimes, to play, to draw, to paint, because then we can draw, talk [...] you must have your own language, because you must understand their world, the universe of the adolescent, and the universe of the child.

On the other hand, in some discourses, the children/ adolescents were invisible in the process of care, especially in the first moment of the embracement process, which is communication. That transformed the communication between professional and user in a unilateral process. The communication is vertical, when the professional exposes information they consider to be necessary to be completed in the treatment of the patient. The information is directed at the adult, and the child or adolescent is only a spectator. The adolescent is expected to understand the message in a similar way to the adult.

(P10 - F51) It is not relevant if it is a child or adolescent, because if it's a child the mother or the father or the aunt will be the ones who have to understand what I am saying, so it's the adult. If the adolescent understands, it's like the adult does.

The embracement in the attention to the health of the child and the adolescent with leprosy was seen as essential since it minimized risks of losses in the attention and in the diagnostic of possible cases, and since it opened doors for the establishment of bonds between the professional, the patient, and the relatives. The proposal of an inclusive and humanized assistance is a strategy that increases the strength of the pillars of the actions to promote the health of the population.

(N3 - F46) The first consultation seems to me the ideal moment to create a bond. He saw he was embraced, he saw someone was interested in treating him, in seeing his family, in seeing everyone, so he sees that that person is interested in treating, so it is easier for him to come.

Embracement is seen as a practice that constitutes the relations of care between health professional and patient. Embracing the demand presented by the population suggests that this demand is being listened to, that its problems are discussed, and it is being considered as valid. That requires, from the professional, a broad look about the health needs the person presents ${ }^{(14-15)}$. 
The discourse of the professionals suggest that embracing is understood as an element that is involved in the entire cycle of assistance of children and adolescents being treated for leprosy. Some workers emphasize embracing as a bridge to establish a bond between them and the patient.

Literature ${ }^{(16)}$ has shown that, through embracing in health, it is possible to establish relations of trust between the actors involved in the practice, such as health workers, patients and families, and trust is the base for this bond to be created.

In a Foucauldian reading, healthcare must be directed as to know the fragile singularities of human beings, establishing a dialectic relation between the disease and the person with the disease $\mathrm{e}^{(13)}$. From this perspective, it is possible to ponder over the healthcare practices from the professional, since health professions have, as the base of their work, the elaboration of relations with individuals, which are permeated by the communicative process. To guarantee that the healthcare offered can take into account the biopsychosocial and cultural needs of a person and their family, it is essential to establish a communication based on a bond.

The workers also mentioned the particularities of the process of communicating with children and adolescents, recognizing that, often, they are offered an assistance that is molded according to that of the adult public. A study on the attention offered in the pediatric outpatient clinic of a hospital showed that the attention offered by the professionals to the patient and family, as well as the use of a language that is adequate to this pairing, were mentioned as positive aspects of the attention ${ }^{(17)}$.

One of the characteristics of the embracing criteria is related to the time spent in the attention. The time spent in the consultation was highlighted, since the patient needs to undergo a dermatological-neurological examination, the disease must be notified, contacts must be investigated, medication must be required and the child/adolescent/ family needs to receive guidance.

However, it stands out that integral healthcare to children and adolescents in the treatment of leprosy requires developing, with this population, healthcare that is focused on health promotion and attention humanization. It should revolver around dealing with the health demands, be they individual or collective, valuing each child and adolescent as social subjects with rights in their process of growing and developing ${ }^{(17)}$. It is important to highlight the importance of the actions of the nurse as the member of the health team who can articulate and mobilize the team itself, considering the specificities of each professional to assure integral healthcare to this population group and the relevance of the actions of nurses, especially in the follow-up consultations.
Starting from the analysis of the time required to learn all demands targeted at an integral care to the children/adolescent with the diagnostic of leprosy, Foucauldian thought ${ }^{(13)}$ states that current healthcare has been increasingly impatient and fast-tracked. To Foucault, this type of practice does not reflect the essence, since "haste" and "impatience" destroy the capacity of the worker to understand deeper issues that exist between the disease and the diseased. The production of healthcare in children and adolescents with leprosy requires the health worker to be careful with regards to the particularities of the situation, taking into account not only their age, but also their cognitive and emotional development.

\section{Clinical practice}

In their discourses on the clinical practices, participants highlighted a distinction between the initial consultation, which included an evaluation to diagnose and determine treatment, and the subsequent monthly follow-up consultations, which lasted from six months up to the discharge of the patient. When considering the particularities of children and adolescents, the health professionals emphasized that it was more difficult to diagnose them based on the dermatological-neurological exam. Regarding the follow-up consultations, the need to sensitize the relatives was mentioned as a way to guarantee that those in contact with the child would be examined and that they would come back to the service if the child presented any changes.

Most participants associated clinical practice to medical history and/or detailed user physical examinations. In clinical practice, clinical evaluations are essential. They include the initial process of a consultation, in which the professional acquires the information reported by the relatives and adolescent or child, in addition to performing the dermatological-neurological examination.

(P5 - F30) First the history, we want to know what the story is, why did the patient come, why are they here, what happened, and during the physical examination we search for skin lesions, and we do the sensitivity tests again.

(OT1 - F48) At first / do this part, the occupational and social evaluation, because that is totally related to my practices, then later we carry out a medical history and then I do what the ministry of health prescribes that we should do in the field of rehabilitation.

Requests for lab exams were also highlighted as procedures inherent to the clinical practices, since, as a 
complementary measure, they are essential to evaluate organic functions and possible adaptations to the medication treatments.

(N7 - F37) we ask for the hepatic function of this patient, urine exams, we usually start at once with an antiparasitic, all that.

(P7 - F35) We start with routine exams, so at first we ask for glycemia, hemogram, because usually the dapsone can lead to anemia, and we'll ask other exams, the biochemical stuff, bilirubin, AST, ALT, hepatic function, G6PD, coagulation tests. We give the medication and the albendazole for the prophylaxis of the strongyloides.

Another issue mentioned by participants was regarding the process of investigation of the disease. They reported that most workers from primary healthcare units have difficulties in diagnosing leprosy in children and need to refer the children to specialized units.

(N7 - F37) [...] sometimes the responses are difficult, especially in children, so, when there's a child, we usually refer them to the specialized service, since diagnosing a child is not that easy. They get confused when answering questions about sensitivity [...]

Another issue pointed out was examining those who got in touch with the child. Many professionals had difficulties investigation the existence of other cases of the disease among those in touch with the child because they resist going to the service.

(N3 - F46) I think the most difficulty thing is examining the contacts. I managed to go to the house of one patient to do the exam, because they wouldn't come to the unit [...]. For another patient, I couldn't examine anyone yet, because even his mother, who brought him that day, she wouldn't let me examine.

In their discourses, participants pointed out that medication treatment was a potential part of the clinical practice.

(P4 - F36) Medication arrives fast, I have no problems, when l ask it comes in 24 hours and I can start it.

The clinical practice, when applied to the context of the Primary Health Care, can be understood as an activity that involves many processes and articulated actions that result in the integral care to the user. Clinical nomenclatures are used in the works of Foucault as he presents the clinical practice as an element of positive accumulation of professional knowledge. The philosopher also states that the clinic takes on a dynamic role within healthcare, since through a constant and careful observation of the diseased person it renews itself at every moment ${ }^{(13)}$.

The professional in the exercise of the clinic is an instrument to unveil the truth in its original sense. However, this practice needs to be systematize in its outcome, from the beginning of the professional meeting with the patient, going through the counseling, the recording of their clinical history, physical exams, and continues to be systematized and organized until the end of the consultation. To this end, Foucauldian thought suggests that the clinic is essential and valuable in healthcare, though not the only one ${ }^{(13)}$.

The Foucauldian analysis presented in "The Birth of the Clinic"states the importance of the professional dominating the biological characteristics of the disease, but that they should not restrict themselves to that. Workers will only be able to increase their knowledge in health if they go beyond the disease through investigating what is behind it, so that they understand the patient as a whole, according to the social context in which they are inserted.

The evaluation of children and adolescents through medical history and physical examinations, as well as the request for exams described by the interviewees, corroborates another study ${ }^{(18)}$, which found that, in addition to promoting health and preventing diseases, these practices aid in the knowledge of the clinical, sociodemographic, and cultural features of the patients.

When discussing the follow-up of children and adolescents with leprosy, the interviewees indicated that the exam of the contacts and the certainty of the diagnostic were limitations presented in their practices. Examining the contacts, whether they live together or are part of a broader social circle, aims to break the chain of disease transmission, as well as avoiding disabilities and physical deformities that can result from a late diagnostic. Also, the exam aims to seek possible sources of infection by the disease, in order to adequately follow-up ${ }^{(19)}$. It is worth emphasizing how important it is to investigate the contacts of children and adolescents, considering that the risk of transmission among people in the same residence is nine times greater, resulting from the continuous and early exposure to the bacillus ${ }^{(20)}$.

The difficulties in diagnosing children was mentioned by the professionals, which they justified by stating that children were not able to be precise as they answered verbally to the dermatological-neurological exam, which requires thermal, pain, and tactile sensitivity tests to check for leprosy. 
A study carried out with children and adolescents under 15 years of age ${ }^{(20)}$ corroborates the findings of this research, as it affirms that the palpation of the peripheral nerves and the carrying out of sensitivity tests constitute problems in the identification of the disease, especially in children.

The medication treatment of leprosy was a positive aspect mentioned by the participants. In their discourses, they reported that the medications were regularly made available by the SUS, and standardized in multidrug therapeutic plans, both paucibacillary and multibacillary, for children and adults, despite the fact that these medication treatments and lab diagnostics are not attractive for the chemical-pharmaceutical industry to invest in researches about ${ }^{(5)}$.

\section{Education in health}

The discourses of participants in the study showed that the activities of health education are developed in events that are specific to leprosy. Some participants cited that there were no specific health education activities about the disease for children and adolescents, and that these activities, instead, took place in general, for whoever was in the waiting room waiting for treatment, regardless of age. The individual guidance during consultations was also mentioned as education in health.

(P5 - F30) It is developed [activities of education in health] when there is a campaign, which usually the district does, when there's the week or the month of something, than we do speeches, talk, etc... There is not regular activity.

As the participants talked about their educational activities, it was possible to see that they carry them out as when they meet the child and/or adolescent and their family and/ or guardians during consultations.

(PT2 - F4) [...] currently, the only activity of education in health we do is during consultation, when we advise the parents or the guardian of the child.

It could be noted that, when participants offer guidance to the children and/or adolescent and their relatives with regards to Hansen' disease, they sometimes focus on the disease. There were, however, different approaches, some marked by biological models, and others by a broader perspective, which considers psychological and social aspects, as to demystify the disease.
(P2 - F45) [...] we start to explain the spot, and then we do the test [...] if we see that they are losing sensitivity already, I start to talk telling the story [...] that the there is a taboo involving it, a lot of prejudice towards Hansen's disease due to that leprosy story, so there is a social prejudice regarding it. We try to soften it by showing that there is a cure [...]

In the context of healthcare practices in leprosy for children and adolescents, it is very important to build a type of knowledge that is mediated by educational activities in health. When considering Foucauldian thought on knowledge and know-how, the author makes a, for lack of a better word, genealogy of knowledge, in a historical investigation of its possibilities ${ }^{(8)}$.

As he brings the dialogue between power and knowledge into the field of health, he analyzes the contribution of said knowledge to the organization of healthcare, emphasizing its practices. In his thought, he values knowledge as the path to reveal the truth. This knowledge will have its productive character recognized as true, indispensable, and necessary in society as long as it is performed in the dimension of freedom ${ }^{(8)}$.

As a result, we can talk about health education as a political, pedagogical, and social practice withing the sphere of healthcare practices, a systematic and continuous process that stems from the principle of health promotion, requiring a reflexive thought that shows reality and leads to the elaboration of transformative actions that lead the person to their autonomy and emancipation, which includes a greater participation in the process of their own care. This health education interpretation regards the individual as a social subject, capable of giving opinions on the decisions about their own health ${ }^{(21)}$.

Educational activities are elements that can increase the engagement of the individual with both individual and collective health. When targeted at the public of children and adolescents, the creativity of these subjects must be encouraged. To subsidize the educational process in health involving children and adolescents, we find theoretical-methodological references that subsidize proposals targeted at this public by using playful techniques, such as games that encourage fantasy but are linked to reality, motivating and involving the participation of the child. The theme can be addressed in more complex approaches when dealing with adolescents $^{(22)}$.

When analyzing the discourse of participants, one finds there are no health education activities in the USFs or in the 
specialized units that are targeted at children and adolescents being treated for leprosy, or to their relatives. This attitude favors isolation, repressing possibilities of collective pacts, of modes of identifying and dealing with social products that hinder health promotion.

The month of January is a trigger for the perception of leprosy as a national health problem since the Ministry of Health made it the official month for campaigns to raise awareness of the disease in the country. However, educational actions cannot be restricted to this moment of the year. Activities on the theme must be continuously put forth, articulated with surveillance actions and the early detection of new cases.

The discourse of health professionals shows that the guidance on leprosy is offered during the consultation of children and adolescents that are carried out from a vertical and traditional perspective. An analogy of this with the Foucauldian thought would suggest that this type of practice involves the idea of exercising a dense power, a type in which knowledge is not practiced as to provide freedom. The exercise of a health education that is committed to the meanings of freedom is based on the development of health education actions that articulate arenas of dialogue for the process of teaching and learning about leprosy, arenas that are committed to the main role of the child and adolescent as subjects with rights ${ }^{(21)}$.

The conversation between professional-child/adolescent-family was not privileged at all moments, since some workers diminished the value of the discourse of children and adolescents in their narratives, making it clear that the child and adolescent were invisible in the process of care.

The workers report in their discourse how important it is to demystify the disease in the guidance they offer in consultation. Foucauldian thought ${ }^{(12)}$ shows that one of the ways to exercise power is through repression, and this repression is connected to the lack of knowledge. The more the ignorance, the more the efficiency of this repressive power. Regarding the idea of exclusion, the author creates an analogy with leprosy patients during the middle ages, in which these individuals were subjected to all manner of rejection. For the author, this type of power was not exercised only towards individuals with leprosy, but also to any individuals considered "abnormal", such as the insane, the children, the criminals, the diseased, the poor ${ }^{(12)}$.

This exclusion model ${ }^{(12)}$, currently translated as stigma or prejudice, has marked the history of leprosy from its beginning until now. As a result, the diagnostic generally impacts the child, adolescent and/or their families. In children and adolescents, this impact takes place in different ways. In the child, it depends on their social and cognitive development level; in the adolescent, it can me more complex, since this is a stage in which profound changes take place, and their identity and self-esteem are still being constructed ${ }^{(21)}$.

\section{GINAL CONSIDERATIONS}

In this study, it was possible to analyze, through the discourses, that the professionals carry out their healthcare practices en masse, due to the high number of consultations and protocol activities defined by the Health System. That is a limitation in the establishment of an assistance that can include the particularities of children and adolescents being treated for leprosy. Therefore, considering Foucauldian references, it is relevant to reflect on the use of normalization to control the bodies of individuals, which can be noted even in the little participation of this public in carrying out their own healthcare.

This research contributes with evidences that highlight the need for reorienting the formation of health professionals to interdisciplinary actions, not only in integral care to the health of children and adolescents with leprosy, but also in healthcare management and practices, highlighting the importance of listening for the professionals who offer primary health care, so that public policies can be drawn that are committed to dealing with the high endemicity of leprosy among children and adolescents.

Therefore, it is necessary to (re)organize healthcare practices in leprosy for the children and adolescent public, as to direct the development of good practices. It is paramount to encourage other studies in the field to be carried out, as to include new perspectives on the theme.

A limitation of this study was the impossibility of aggregating the data from the observations made during the attention offered by the professionals to the children and adolescent or their relatives, since that would mean interfering in the spontaneity of the interrelations between the actors involved in the process of caring.

\section{REFERENCES}

1. Freitas BHBM, Cortela DCB, Ferreira SMB. Trend of leprosy in individuals under the age of 15 in Mato Grosso (Brazil), 2001-2013. Rev Saúde Pública. 2017;51:28. doi: https://doi.org/10.1590/s1518-8787.2017051006884

2. Pan American Health Organization [Internet]. Washington: PAHO; c2019- [cited 2020 Jan 10]. Leprosy; [about 1 screen]. Available from: http://apps.who.int/ neglected_diseases/ntddata/leprosy/leprosy.html

3. Ministério da Saúde (BR) [Internet]. Brasília (DF); c2019- [cited 2020 Jan 9]. Hanseníase: 0 que é, causas, sinais e sintomas, tratamento, diagnóstico e prevenção; [approx. 1 screen]. Available from: http://saude.gov.br/saudede-a-z/hanseniase 
4. Narang T, Kumar B. Leprosy in children. Indian J Paediatr Dermatol. 2019 [cited 2020 Jan 10];20(1):12-24. Available from: http://www.ijpd.in/text. asp?2019/20/1/12/247542

5. Menezes MLN, Figueiroa MN, Monteiro EMLM, Beserra AA, Fernandes MJSS, Santana ADS. Leprosy in subjects under 15 years: epidemiological analysis in Brazil. Int Arch Med. 2017;10. doi: https://doi.org/10.3823/2495

6. Pinheiro MGC, Miranda FAN, Simpson CA, Carvalho FPB, Ataide CAV, Lira ALBC. Understanding "patient discharge in leprosy": a concept analysis. Rev Gaúcha Enferm. 2017;38(4):e63290. doi: https://doi.org/10.1590/1983-1447. 2017.04.63290

7. Foucault M. Em defesa da sociedade: curso no Collège de France (1975-1976). 2. ed. São Paulo: WMF Martins Fontes; 2016.

8. Foucault M. A Arqueologia do saber. 8. ed. Rio de Janeiro: Forense Universitária; 2013.

9. Foucault M. A Ordem do discurso. 24. ed. São Paulo: Loyola; 2013.

10. Minayo MC. 0 desafio do conhecimento: pesquisa qualitativa em saúde. 14. ed. São Paulo: Hucitec; 2014

11. Bardin L. Análise de conteúdo. 6. ed. São Paulo: Edições 70; 2011.

12. Foucault M. Os anormais: curso no Collège de France (1974-1975). 2. ed. São Paulo: WMF Martins Fontes; 2014

13. Foucault M. 0 nascimento da clínica. 7. ed. Rio de Janeiro: Forense Universitária; 2015.

14. Fortuna CM, Oliveira KF, Feliciano AB, Silva MV, Borges FA, Camacho GA, et al. Embracement as an analyzer of the relationships between professionals, managers and users. Rev Esc Enferm USP. 2017;51:e03258. doi: https://doi. org/10.1590/S1980220X2016003303258

15. Moreira CP, Torrenté MON, Jucá VJS. Análise do processo de acolhimento em um Centro de Atenção Psicossocial Infantojuvenil: considerações de uma investigação etnográfica. Interface (Botucatu). 2018;22(67):1123-34. doi: https://doi.org/10.1590/1807-57622017.0500
16. Rocha SA, Spagnuolo RS. Acolhimento na visão complexa: ação coletiva emergente na Equipe de Saúde da Família. Saúde Debate. 2015;39(104):12435. doi: https://doi.org/10.1590/0103-110420151040394

17. Lira HG, Machado CVB, Del Ciampo IRL, Del Ciampo LA. Comunicação médico - paciente em ambulatórios de pediatria de um hospital universitário. Medicina (Ribeirão Preto). 2015;48(5):425-30. doi: https://doi.org/10.11606/issn.21767262.v48i5p425-430

18. Serrano-Coll H, Mora HR, Beltrán JC, Duthie MS, Cardona-Castro N. Social and environmental conditions related to Mycobacterium leprae infection in children and adolescents from three leprosy endemic region of Colombia. BMC Infect Dis. 2019;19:520. doi: https://doi.org/10.1186/ s12879-019-4120-2

19. Ministério da Saúde (BR), Secretaria de Vigilância em Saúde, Departamento de Vigilância das Doenças Transmissíveis. Guia prático sobre a hanseníase. Brasília, DF; 2017 [cited 2019 Aug 10]. Available from: https://portalarquivos2.saude. gov.br/images/pdf/2017/novembro/22/Guia-Pratico-deHanseniase-WEB. pdf

20. Pradhan S, Nayak BP, Dash G. Childhood leprosy: a review. Indian J of Paediatr Dermatol. 2019;20(2):112-6. doi: https://doi.org/10.4103/ijpd. IJPD_47_18

21. Monteiro EMLM. Mercês AA, Cavalcanti ACBS, Cavalcanti AMTS, Lacerda ACT, Silva RDM, et al. Culture circle as a teaching approach in the education of teenager health multipliers on leprosy awareness. Health. 2015;7(14):181323. doi: https://doi.org/10.4236/health.2015.714199

22. Vygotsky LS. A formação social da mente. São Paulo: Martins Fontes, 2007.

\section{Acknowledgments:}

The Institution for Higher Education Personnel Improvement (CAPES).

\section{- Corresponding author:}

Joana D'arc Conceição Pinheiro de Oliveira

E-mail: joanadarcque@hotmail.com

\section{Associate editor:}

Wiliam Wegner

Received: 10.29.2019

Approved: 02.12.2020

\section{Editor-in-chief:}

Maria da Graça Oliveira Crossetti 